\title{
Acidente com material biológico: uma abordagem a partir da análise das atividades de trabalho'
}

\section{Accidents with biological material: an approach based on the analysis of work activities}

\author{
Sandra Donatelli \\ Fundação Jorge Duprat Figueiredo de Segurança e Medicina do \\ Trabalho. Centro Técnico Nacional. São Paulo, SP, Brasil. \\ E-mail: donatelliðfundacentro.gov.br \\ Rodolfo Andrade de Gouveia Vilela \\ Universidade de São Paulo. Faculdade de Saúde Pública. \\ São Paulo, SP, Brasil. \\ E-mail: ravilelaœusp.br \\ Ildeberto Muniz de Almeida \\ Faculdade de Medicina de Botucatu. Botucatu, SP, Brasil. \\ Universidade Estadual Paulista. Botucatu, SP, Brasil. \\ E-mail: ialmeidaœfmb.unesp.br \\ Manoela Gomes Reis Lopes \\ Universidade de São Paulo. Faculdade de Saúde Pública. \\ São Paulo, SP, Brasil. \\ E-mail: lopes.manoelaœusp.br
}

\section{Correspondência}

Sandra Donatelli

Fundacentro/CTN

Rua Capote Valente, 710, Cerqueira César. São Paulo, SP, Brasil.

CEP 05409-002.

\section{Resumo}

Trata-se de estudo qualitativo feito em hospital universitário, cujo objetivo foi analisar o trabalho de auxiliares e técnicos de enfermagem, categoria mais numerosa entre os profissionais de saúde e mais sujeita à incidência de acidentes de trabalho. Este hospital conta com um pouco mais de 2.000 profissionais de enfermagem. Foram utilizados dois métodos de análise. 1) A Análise Coletiva do Trabalho (ACT), que consiste em reuniões com pequenos grupos de trabalhadores explicando seu trabalho. Foram realizadas quatro reuniões, com 34 participantes, quase todos do sexo feminino; 2) O Modelo de Análise e Prevenção de Acidentes (MAPA), que foi utilizado para compreender um acidente ocorrido em uma das clínicas do hospital, com um acidentado que aceitou participar do estudo. Os resultados revelaram que as rotinas de trabalho caracterizam-se por rol de tarefas de cuidados aos pacientes, marcado por grande variabilidade no cotidiano de suas atividades constantemente interrompidas com sobreposição de tarefas decorrentes de demandas urgentes, além de problemas em aspectos organizacionais na situação que originou o acidente, bem como, a fragilidade do sistema de gestão de segurança do trabalho no hospital.

Palavras chave: Acidentes do Trabalho; Exposição Ocupacional a Material Biológico; Análise Coletiva do Trabalho; Análise de Acidente; Prevenção.

\footnotetext{
1 Estudo realizado para obtenção do grau de Mestre. Cumprido no Programa de Pós-graduação em Saúde Pública da Faculdade de Saúde
} Pública da USP, 2011 a 2013. 


\section{Abstract}

The present qualitative study was carried out in a university hospital, with the purpose of analyzing the work of nursing assistants and technicians, the most numerous category among health professionals and more prone to accidents in the workplace. This hospital has little more than 2.00o nurses. Two methods of analysis were used. 1) The Collective Analysis of Work (ACT - Análise Coletiva do Trabalho), consists of meetings with small groups of workers who explain their work. Four meetings were scheduled, and 34 participants, almost all of them females, attended. 2) The Model for Analysis and Prevention of Accidents (MAPA), a unique method for the occupational accidents analysis was held in one of the hospital clinics, with an injured worker that agreed to participate. The results revealed that work routines consist of a list of patients care tasks, characterized by a great variability in their daily work schedule. Many interruptions and overlapping tasks arise from urgent demands, besides issues in the organizational aspects of the situation that engendered the accident, as well as the fragility of the system of work safety in the hospital.

Keywords: Work Accidents; Occupational Exposure to Biological Material; Collective Work Analysis; Accidents Analysis; Prevention.

\section{Introdução}

Em relatório sobre os riscos de exposição a material biológico, a World Health Organization (2003) estimou o número de trabalhadores da saúde por volta de 35 milhões, dos quais, entre dois e três milhões correriam o risco de exposições percutâneas de patógenos veiculados pelo sangue a cada ano, incluindo os vírus da imunodeficiência humana (HIV), hepatite B (HBV) e hepatite C (HCV) (WHO, 2003).

A literatura revela que existem mais de 60 diferentes patógenos aos quais estão expostos os profissionais de saúde, quando em contato com sangue ou fluido corporal contaminado, e que os profissionais mais atingidos são os das equipes de enfermagem, dentre os quais os auxiliares e técnicos de enfermagem (Rapparini; Reinhardt, 2010). Estas equipes são compostas em sua maioria por mulheres na faixa etária de 20 a 40 anos (Sêcco et al., 2003; Silva et al., 2010; Kon et al., 2011; Sabbah et al., 2013).

Os profissionais de saúde que trabalham em áreas de operação/prestação de cuidados, de emergência, salas cirúrgicas e laboratórios têm um risco maior de exposição, bem como os profissionais de limpeza, de resíduos ou coletores cujas funções envolvem a manipulação de materiais contendo material contaminado (Machado; Assunção, 2012). A maioria das exposições ocorre nos quartos dos pacientes, além de incidentes em salas de cirurgia, serviços de emergência e unidades de terapia intensiva (Centro..., 2011).

O risco de infecção para os profissionais de saúde depende de fatores como a prevalência das doenças na população atendida, das condições clínicas do paciente-fonte, da presença e do volume de sangue envolvido, do tamanho da lesão e do correto tratamento após a exposição (Brasil, 2006, 2010). As lesões consideradas mais recorrentes ou comuns são as percutâneas originadas por picada de agulha ou outro material cortante (bisturis, lancetas e vidros quebrados), as lesões mucocutâneas originadas por respingo de sangue ou de fluido corporal no contato com os olhos, nariz, boca ou lesão já existente no profissional ou, ainda, do sangue/fluidos em contato com pele não intacta (WHO, 2003; Spricigo; Madureira, 2003; Rapparini; Reinhardt, 2010; Kon et al., 2011). 
No Brasil, acidentes de trabalho com exposição a material biológico são de notificação compulsória, devendo ser registrados no Sistema de Informações de Agravos de Notificações (SINAN) (Brasil, 2011). São acidentes considerados emergenciais, pois o tratamento precisa ser iniciado logo após a ocorrência do fato para que possa ser eficaz (Brasil, 2011).

No registro do Anuário Estatístico da Previdência Social, esse tipo de acidente tem aumentado anualmente. Em 2010, foram registrados 48.311 casos; em 2011, 44.185. (Brasil, 2012).

O Ministério da Saúde, em busca da prevenção desses eventos, elaborou o manual de Diretrizes Gerais para o Trabalho em Contenção com Agentes Biológicos, que tem por finalidade definir requisitos mínimos para o trabalho seguro com agentes biológicos (Brasil, 2010). Uma de suas principais recomendações refere-se aos acidentes por material perfurocortante, que devem ser avaliados imediatamente após o ocorrido, utilizando-se de condutas, que diferem para cada tipo de vírus, para verificação das exposições ocupacionais a materiais biológicos potencialmente contaminados com o HIV, vírus da imunodeficiência humana; o HBV, vírus da hepatite B; e o HCV, vírus da hepatite C; (Brasil, 20o6).

O Ministério do Trabalho, por sua vez, elaborou a Norma Regulamentadora-32 (NR 32), publicada pela Portaria n. 485, de 11 de novembro de 2005, com recente alteração feita pela Portaria n. 1.748, de 30 de agosto de 2011, que introduziu o Anexo III, prescrevendo a obrigatoriedade do Plano de Prevenção de Riscos de Acidentes com Materiais Perfurocortantes (Brasil, 2005).

A mesma norma define riscos biológicos, bem como regras e orientações para a implantação de medidas de proteção e gestão de segurança à saúde dos trabalhadores da área, a partir da elaboração de programas voltados à segurança dos trabalhadores. Prevê, ainda, a capacitação continuada, a disponibilidade de materiais em locais de fácil acesso e também estabelece diretrizes gerais para procedimentos de movimentação de pacientes (Brasil, 2005).

Esses regulamentos visam aprimorar e permitir maior controle dos acidentes, bem como prover os órgãos internos dos estabelecimentos de saúde de parâmetros para realizar planos preventivos para a promoção e proteção da integridade física e psíquica dos profissionais da saúde, que estão diariamente expostos aos agentes biológicos. 0 descumprimento das referidas legislações submete os estabelecimentos de saúde a punições legais, o que torna obrigatória a adoção das medidas de proteção, bem como o fornecimento de equipamentos aos profissionais.

Das medidas preventivas e de proteção preconizadas constam as denominadas Precauções Padrão, adotadas no Brasil, que consistem em conjunto de práticas (por exemplo, lavar as mãos após qualquer contato com pacientes; descarte seguro de material cortante; uso de luvas, máscaras, óculos, aventais; cobrir mucosas lesionadas) projetadas para reduzir o risco de transmissão de micro-organismos (patógenos) por meio das substâncias úmidas do corpo (sangue, fluidos corporais), oriundas de fontes reconhecidas ou não de infecção hospitalar e que devem ser utilizadas independentemente do tipo de doença do paciente (Garner, 1996; Siegel, 2007).

Os serviços de saúde constituem-se em ambientes complexos, que apresentam diferentes riscos aos trabalhadores da saúde, e os acidentes de trabalho com perfurocortantes continuam a ser um problema quanto ao risco de infecção por material biologicamente contaminado, pois há possibilidade de transmissão de algum agente patógeno pelo sangue, como nos casos das hepatites B e C e do HIV. Tratam-se de doenças graves em que, mesmo não havendo a soroconversão, implicam sofrimento para o acidentado e para sua família, além de envolverem custos financeiros altos com tratamentos. Neste sentido, entende-se que este tipo de acidente deve ser evitado; para tanto, se faz necessário compreender sua origem.

O assunto é duplamente relevante para a saúde pública: pela sua magnitude epidemiológica, alcançando importante segmento da classe trabalhadora que, por outro lado, desempenha papel estratégico no cuidado da saúde da população.

A visão tradicional da segurança baseia-se no dueto: ato inseguro/condição insegura, que foi desenvolvida nos anos de 1930, e vem conseguindo se manter no modo de pensar e planejar a gestão e organização dos sistemas de segurança das empresas e, infelizmente, também no ideário popular. Olhar para o acidente sob esta forma reducionista reflete um modelo de análise que considera o evento aciden- 
te como um fato simples, com origem geralmente centrada em uma única causa, qual seja, sempre decorrente das falhas dos profissionais da área de saúde ou de suas omissões e/ou de falta de atenção ou desrespeito às normas vigentes nos procedimentos de segurança (Reason, 1990; Vilela, 2003; Vilela; Iguti; Almeida, 2004)

A abordagem tradicional cria outra dificuldade para se seguir adiante ao trabalharmos com a temática dos acidentes de trabalho. Tal dificuldade está instalada no fato de que o próprio trabalhador acidentado tende a considerar que foi negligente ou teve falta de atenção ou mesmo comportou-se fora das "regras" prescritivas de segurança (Oliveira, 2007; Nagai et al., 2007).

O que parece se esconder sob essa hipótese toma assento na preocupação excessiva de gestores em elaborar novos modelos de normas e regras de procedimentos para dominar as variações no trabalho e controlar ao máximo todo o processo produtivo assegurando, assim, uma melhor efetividade nos resultados planejados de produção e produtividade, partindo do pressuposto de que a obediência ao procedimento operacional, por si só, pudesse eliminar todas as possibilidades de riscos existentes. Desconsidera-se a distância entre as orientações ou modelos normatizadores prescritos e o trabalho realizado de fato (efetivo), o real (Lima, 2005).

Em recente artigo, Hollnagel e Besnard (2012) descrevem seis premissas básicas no âmbito da segurança de sistemas industriais presentes no cotidiano das empresas e as classificam como mitos. Destacam-se entre esses mitos os erros humanos, a não observação aos procedimentos de segurança, a ideia de "segurança em primeiro lugar", etc., sendo que a primeira é largamente difundida como causa principal dos acidentes, corroborando com a ideia de “culpa da vítima” (Hollnagel; Besnard, 2012).

As premissas são chamadas mitos da segurança, pois podem facilitar o seu gerenciamento, mas também fragilizá-la, além de serem ideias compartilhadas por um grande número de pessoas, dentro e fora das empresas; elas expressam um conjunto de atitudes e valores que determinam as decisões e ações relacionadas com a segurança; não são questionadas ou percebidas e são resistentes a mudanças (Hollnagel; Besnard, 2012, p. 18).
Explicam os autores que a segurança deve ser compreendida como um processo, algo que o sistema faz e está em constante negociação e não como algo que o sistema possui. Outro ponto a ser considerado, nessa abordagem sistêmica, é o de que a segurança deve ser entendida mais para a melhoria constante de seu sistema do que para reduzir aspectos que não funcionam bem, ou seja, que os indicadores devem medir mais o que funciona bem para melhorar sua capacidade de resposta sob condições variáveis ou em mudanças, e não manter-se focada só no que vai mal, visando reduzir apenas os eventos adversos (Hollnagel; Besnard, 2012).

A abordagem sistêmica buscada neste estudo teve como um de seus objetivos mostrar a relevância de se realizar a análise do trabalho, que procura conhecer as diferentes realidades das situações de trabalho cotidianas para, em um segundo momento, realizar a análise do acidente. $\mathrm{O}$ modelo sistêmico destaca a complexidade que envolve o evento acidente e procura realizar a análise a partir da compreensão das características do funcionamento dos sistemas na sua integralidade de modo oposto ao da abordagem tradicional, que divide e decompõe um sistema em partes analisando apenas aspectos que são mais próximos aos eventos acidentes/ incidentes.

Este artigo teve por objetivo evidenciar os aspectos e o processo de trabalho que concorrem para a ocorrência dos acidentes de trabalho com material biológico e, para alcançá-lo, foram utilizados dois métodos de análise para elucidar as diversas situações de trabalho em interação durante o cotidiano dos auxiliares e técnicos de enfermagem de um hospital público do Brasil.

\section{Métodos}

Para alcançar os objetivos citados, optou-se por descrever e estudar as rotinas e atividades de trabalho dos auxiliares de enfermagem (AE) e técnicos de enfermagem (TE), pois verificou-se, após confirmação junto ao Serviço Especializado de Segurança e Medicina do Trabalho (SESMT) do hospital, tratar-se da categoria mais atingida por acidentes com risco de contaminação por material biológico; além de analisar um acidente de trabalho com vistas a 
conhecer os motivos e causas que poderiam estar presentes nas suas origens.

O estudo foi realizado em um hospital público que tem como finalidades o ensino, a pesquisa e a prestação de serviços de alta complexidade à comunidade. Foram utilizados dois métodos: a Análise Coletiva do Trabalho - ACT (Ferreira, 1993), para compreender os aspectos das situações de trabalho; e o Modelo de Análise e Prevenção de acidentes - MAPA, para a análise de acidentes de trabalho (Almeida; Vilela, 2010).

A ACT consiste em realizar reuniões com pequenos grupos de trabalhadores que aceitem falar sobre seu trabalho. Para tanto, utiliza-se como pergunta condutora o que você faz no seu trabalho?. Para a realização das reuniões conta-se com a participação voluntária dos trabalhadores, preservando-se seu anonimato. As reuniões são, preferencialmente, gravadas em áudio para posterior elaboração de texto. Este método não possui uma regra rígida para a elaboração de categorias de análise, o que permite ao pesquisador guiar-se por pontos/tópicos discutidos nas reuniões que podem ter sido destacados pelos trabalhadores. Optou-se por analisar o trabalho seguindo como roteiro a rotina diária descrita pelos profissionais, com o intuito de identificar aspectos do trabalho que caracterizassem seu conteúdo, seu modo organizacional e das relações estabelecidas no ambiente de trabalho, que foram agrupados de acordo com temas que eram tratados pelos participantes e organizados de modo a permitir uma fiel exemplificação da realidade cotidiana.

A ACT incluiu seis reuniões, das quais participaram 34 auxiliares e técnicos de enfermagem, ocorridas no período de novembro de 2012 a fevereiro de 2013. O método preconiza a participação voluntária dos trabalhadores. Neste sentido, as chefias de enfermagem haviam sido informadas com uma palestra de apresentação sobre o projeto e, nas datas marcadas para as reuniões, liberavam os AE/TE que quisessem participar, desde que isto não afetasse o atendimento aos pacientes. Antes do início da reunião, explicava-se a pesquisa e quem desejasse participar permanecia na reunião.

O MAPA consiste em um roteiro flexível para que pesquisadores possam buscar informações necessárias à compreensão da situação complexa que envolve o acidente, desde seus antecedentes imedia- tos até os remotos. Ele se apoia em vários conceitos como os da ergonomia da atividade, da psicologia do trabalho, da engenharia de segurança, etc.

0 roteiro do MAPA, além de sistematizar informações sobre as empresas e vítimas, orienta para os seguintes passos: (a) Descrição do trabalho habitual, suas variabilidades mais frequentes e os ajustes ou regulações usualmente adotados pelos trabalhadores para lidar com as mesmas; (b) Descrição do acidente propriamente dito, que se subdivide em (b1) Análise de mudanças; (b2) Análise das barreiras e de seu funcionamento na prevenção e proteção do operador; (c) Análise de aspectos conceituais e que auxiliam na compreensão do comportamento dos operadores; (d) Medidas adotadas pela empresa depois do acidente; (e) Conclusão e recomendações para a prevenção de novos eventos. As análises de mudanças e barreiras são concluídas em termos de falhas gerenciais e organizacionais tanto na gestão de saúde e segurança do trabalho, como na gestão da produção propriamente dita, ou em aspectos específicos da gestão de manutenção, de pessoal, de materiais, de projetos etc. A contribuição da ampliação conceitual pode ajudar a revelar falhas na concepção de sistemas técnicos, assim como no desenho das alças de controle sugeridas em relação aos perigos e riscos identificados e na operação desses sistemas, nas interações entre subsistemas e ainda na desconsideração de características psicoafetivas dos trabalhadores que realizam as atividades. As conclusões da análise são sintetizadas como rede de fatores em interação com origens nos aspectos apontados (Almeida; Vilela, 2010).

Para a análise dos acidentes com o MAPA, foi solicitado ao SESMT do hospital que verificasse os acidentes com perfurocortantes, acontecidos em período não superior a um mês (a partir de novembro de 2012, início da pesquisa). Dos dois acidentes estudados um deles é objeto do presente artigo. Foram feitas entrevistas com os acidentados e com as chefias, fotografias do ambiente e observação de procedimento similar ao do acidente relatado neste texto também puderam ser feitas. Para este acidente, foram feitas seis visitas à clínica no período de período novembro de 2012 a fevereiro de 2013.

O projeto foi submetido aos Comitês de Ética em Pesquisa da Faculdade de Saúde Pública da Universi- 
dade de São Paulo e do Hospital, e teve aprovação de ambos, pelos pareceres de números 107.535, 103.512, respectivamente. A Pesquisa é parte integrante do projeto Temático: "Acidente de trabalho da análise sócio técnica à construção social de mudanças" (FAPESP 12/04721-1).

\section{Resultados e discussão}

A atividade de trabalho dos AE/TE consiste em executar os cuidados a pacientes. A produção de serviços de saúde para estes profissionais tem como núcleo central a produção de cuidados, que têm início na divisão de tarefas, contida na própria lei de regulamentação do exercício da profissão, diferenciando detalhes sobre as tarefas de um $\mathrm{AE}$ e as de um TE, criando uma hierarquia entre profissionais tidos como aptos a "exercerem atividade de nível médio". À época do estudo, os AE e os TE exerciam as mesmas tarefas e atividades (Quadro 1).

0 trabalho exercido pelos AE/TE continha características específicas: ininterrupto e coletivo, pois visava garantir a continuidade da assistência aos pacientes. Organizado em rotinas diárias interrompidas de acordo com uma série de situações ou intercorrências. A alteração na sequência das tarefas causava desconforto e ansiedade nos profissionais, que poderiam deixar de fazer alguma atividade de cuidado a algum paciente.

É rotina. Porque, se a gente sai dessa rotina, a gente se perde daí acontece alguma coisa, alguma intercorrência. $\varepsilon$ também atrasa um pouco.
As rotinas de trabalho consistem em conjunto de práticas que orientam as tarefas a serem realizadas e o modo próprio de sua realização. Abrangem os seguintes pontos: receber o plantão; aferir os controles ou sinais vitais dos pacientes (pressão arterial, temperatura, pulso, respiração, grau de dor); verificar as prescrições médicas e deixar os medicamentos separados para os horários de medicação; realizar a higienização do paciente ou encaminhar para o banho; fazer as trocas de roupas de cama; realizar as anotações no formulário próprio de cada paciente; e auxiliar nos momentos das refeições. Às vezes, fazer os encaminhamentos (levar o paciente para realizar algum exame em outro setor) ou ir buscar algum medicamento que faltou na farmácia.

São as chefias e a diretoria de enfermagem que determinam as rotinas que seguem as especificidades de cada clínica, de acordo com as especialidades médicas.

A passagem do plantão consiste em uma atividade importante para assegurar a organização da rotina e a continuidade da prestação de assistência ao paciente. Seu conteúdo informa sobre o estado do paciente, as possíveis intercorrências e os tratamentos realizados, questões relevantes ou pendências sobre os mesmos.

Essa troca de equipes de enfermagem (a turma que entra e a que sai) poderá acontecer no posto de enfermagem, ou com as equipes passando na porta de cada quarto. As informações são trocadas de modo oral; o prontuário do paciente (também chamado de prancheta, papeleta ou casinha) não é

\section{Quadro I - Tarefas e atividades de auxiliar e técnico de enfermagem segundo regulamentação do exercício da enfermagem, Brasil}

\begin{tabular}{|c|c|}
\hline Auxiliar de enfermagem & Técnico de enfermagem \\
\hline Observar, reconhecer e descrever sinais e sintomas; & $\begin{array}{l}\text { Participar da programação da assistência de } \\
\text { enfermagem; }\end{array}$ \\
\hline Executar ações de tratamento simples & $\begin{array}{l}\text { Executar ações assistenciais de enfermagem, exceto } \\
\text { as privativas do Enfermeiro, observado o disposto no } \\
\text { parágrafo único do art. II desta lei; }\end{array}$ \\
\hline Prestar cuidados de higiene e conforto ao paciente; & $\begin{array}{l}\text { Participar da orientação e supervisão do trabalho de } \\
\text { enfermagem em grau auxiliar; }\end{array}$ \\
\hline Participar da equipe de saúde. & Participar da equipe de saúde. \\
\hline
\end{tabular}

Fonte: (Brasil, 1986). 
levado juntamente para serem feitas as anotações. Alguns profissionais fazem anotações pessoais para melhor recordar as informações transmitidas, embora não seja uma prática geral, como se nota pela fala a seguir:

Deixa eu explicar. A cada troca de pessoas que trabalham na unidade a gente passa plantão. Então assim, o plantão não encerra. Não existe um início e um fim. Existe a continuidade do trabalho durante 24 horas. O paciente que está ali internado e chega outro, não para, então éfluxo contínuo.

Dos problemas referidos sobre as trocas de plantão, destacam-se a falta de tempo para que sejam passadas informações e o atraso na chegada dos colegas como os mais frequentes. A falta de tempo refere-se à coincidência entre os horários de chegada e saída das equipes. Os horários das trocas de plantão são organizados de modo fixo $(7 \mathrm{~h}$; $13 \mathrm{~h}$; 19h), tanto para o início do turno de trabalho como para o término, por exemplo: uma equipe sai às $7 \mathrm{~h}$ e a outra irá entrar às 7 h. Assim, não há um tempo previsto para que as equipes estejam mutuamente nos postos de enfermagem para essas trocas, o que obriga os profissionais a chegarem mais cedo, ou saírem mais tarde para realizar esse processo de troca de informações.

Essas situações de atrasos e faltas geram queixas e discussões da parte de quem permanece esperando para ser substituído. Isso se agrava com o PIN - prêmio de incentivo -, uma medida criada como incentivo para que atrasos e faltas não aconteçam, mas que acirra a situação de descontentamento e cria "panelas" nas equipes de trabalho. $\mathrm{Na}$ literatura, estudos confirmam estes achados e sugerem a necessidade de mudanças no planejamento do horário de trocas de turno que coincidem com a passagem dos plantões, reforçando o fato de que fatores organizacionais podem interferir nas condições de saúde dos profissionais, bem como a necessidade de adequações para a melhoria da organização do trabalho (Meissner et al., 2007; Osório et al., 2011).

A equipe de enfermagem que acabou de entrar ou pegar o plantão e dará continuidade aos cuidados, vai retirar as últimas medicações do carrinho, separá-las com as etiquetas correspondentes aos pacientes, deixando-as organizadas e prontas para os horários de sua administração. Atividade que exige atenção. Após a administração, os AE/TE fazem uma bolinha na linha do formulário de prescrição médica onde consta o nome da medicação e o horário. Esta marca (bolinha) é entendida pelas equipes de profissionais como um sinal de que a medicação foi administrada ao paciente no horário certo. 0 pessoal do turno da noite faz a bolinha com caneta vermelha. Este sinal atenua um pouco outro problema, o de que nem sempre os AE/TE conseguem fazer a anotação de enfermagem logo depois de realizado o procedimento.

As anotações consistem em registros efetuados pela equipe de enfermagem, com a finalidade de fornecer dados sobre a assistência/cuidado prestado e de assegurar a comunicação entre os profissionais, garantindo a continuidade das informações sobre os pacientes durante as 24 horas do dia. Assim, são indispensáveis na medida em que compõem um sistema sobre os eventos acontecidos com os pacientes e possibilitam verificar se as ações realizadas seguiram corretamente as prescrições médicas.

Tudo que a gente faz no paciente tem que estar escrito, élei. A gente tem que cumprir a legislação. Então assim: se eu não anotar, eu não cuidei, teoricamente.

Os AE/TE utilizam uma "colinha" como estratégia de regulação, para driblar a situação de não anotar o cuidado imediatamente após sua execução.

A maioria das meninas leva uma folhinha onde elas anotam.

Trata-se de um papel no qual anotam as tarefas executadas e as medições dos sinais vitais para que, num momento mais "tranquilo", possam transcrever as informações na folha de anotação de enfermagem. Esta estratégia é relatada como cotidiana, porém gera apreensão, já que se refere às responsabilidades legais. A anotação de enfermagem é considerada um instrumento legal de defesa para o profissional. Toda anotação descrita no formulário precisa conter a identificação do profissional, com sua assinatura, data e hora de realização do procedimento.

Pra gente fazer os controles, por exemplo, a gente leva o papel e anota no papel a pressão, temperatura, pulso. 
Esta situação revela dois pontos críticos: primeiro, o da não disponibilização da informação sobre o paciente em caso de urgência; segundo, o da possibilidade dos AE/TE terem de priorizar certas atividades da rotina em detrimento da anotação dos procedimentos realizados, ou ter que disputar o prontuário com outra equipe de profissionais (médicos, fisioterapeutas etc.).

Não, ele [prontuário] é muito disputado entre os médicos, entre os enfermeiros auxiliares, entre a nutricionista, fisioterapeuta, tudo.

O próximo passo é o da higienização dos pacientes. A regra é a de que deve ser feita preferencialmente no turno da manhã, considerado como o de maior volume de tarefas a serem executadas. Os banhos dos pacientes são basicamente de três tipos: banho de leito (feito em pacientes que não têm condições de sair da cama); banho de assistência (em pacientes que podem ir ao banheiro, mas em razão de seu estado de saúde precisam de auxílio); banho sozinho (paciente que consegue tomar banho sozinho sem assistência). Os banhos de leito são mais demorados e geralmente são realizados em duplas, porém, em alguns casos, quando, por exemplo, falta algum colega, eles são feitos por um único profissional. Isso demanda um tempo maior e, por vezes, atrasa outras atividades. Esta tarefa é relatada como uma das que exigem, além de mais tempo, maior esforço físico por parte dos profissionais, principalmente o banho no leito, em que o paciente não consegue colaborar com sua movimentação.

É complicado vocêdar banho num paciente sozinha. Às vezes, um paciente magrinho, pequenininho é fácil, mas tem paciente pesado, grande, obeso, ou que tem dreno, com um monte de coisa.

Estas são as principais etapas da rotina das clínicas que, após os banhos, "teoricamente" se restringiriam às medicações de horário programado. Porém os pacientes precisam de cuidados e atenção constante, assim, essa rotina é interrompida o tempo todo. A campainha toca porque o paciente está com dor, ou precisa de outro banho, ou há necessidade de trocar curativos, levar um paciente para fazer exame em outro local/setor do hospital etc.
Acabou essa parte, essa rotina nos seus quartos, a gente parte para curativo. Tem curativo, às vezes, é pequeno, é só um sorinho. Como tem curativos maiores, às vezes, a gente para um pouquinho para dar a medicação, que está se aproximando das dez horas, com mais emergência, e depois volta para trás para fazer os curativos. Quando dá para fazer tudo ao mesmo tempo, você faz.

As rotinas nas clínicas podem variar porque, às vezes, a quantidade de pacientes para um $\mathrm{AE} /$ TE cuidar em determinado dia fica acima da média diária que seria de 4 ou 5 para cada profissional. Isto ocorre em razão do grau de complexidade da doença e, consequentemente, do tratamento exigido; e das intercorrências - "Intercorrência é um problema." -, um momento considerado crítico, pois implica no fato de o paciente estar passando por alguma alteração no seu estado de saúde que foge ao que está sendo esperado pela evolução do tratamento.

A jornada de trabalho da equipe de profissionais de enfermagem divide-se em três turnos, dois de 6 horas e um de 12 horas de trabalho (das 7 h às 13 h; das 13 h às $19 h$; das 19 h às 7 h). 0 profissional é contratado pelo hospital através da realização de concurso público, gerando um vínculo empregatício de caráter público regido pela CLT (Consolidação das Leis do Trabalho). Esse regime de trabalho será de 30 horas semanais, com um salário um pouco maior do que o mínimo estadual, e com direito a benefícios especificados em lei.

Em razão dos baixos salários, há alguns anos alguns dos profissionais do hospital eram também contratados por fundação ligada ao hospital, com o objetivo de tentar equiparar os salários dos servidores aos do mercado. Assim, criou-se um duplo vínculo de trabalho para profissionais de quase todas as categorias, o que implica no aumento de 1o horas semanais na carga horária de trabalho dos $\mathrm{AE} / \mathrm{TE}$ que possuem esse tipo de vínculo, passando de 30 horas para 40 horas semanais. Tal contratação não vem sendo mais realizada, porém existem profissionais remanescentes dela, são os chamados “complementaristas", porque complementam o salário com este tipo de vínculo de emprego.

Eles chamam a gente de complementarista porque a fundação complementa o salário. Só o salário do hospital é muito pouco. 
Também pode acontecer de alguns profissionais possuírem duplo vínculo com outro empregador que não o Estado, como um hospital particular ou uma clínica.

As escalas de trabalho e os plantões são organizados mensalmente pelas chefias de enfermagem das clínicas. Na sua elaboração, a distribuição dos profissionais é feita de modo a balancear as jornadas (30 ou 40 horas semanais) com a necessidade das folgas obrigatórias por lei - as licenças, os finais de semana e as férias - e dos plantões remunerados (plantões extras de 6 horas), que poderiam ser feitos até o número máximo de dez por mês (à época do estudo), o que implicava em um acréscimo importante ao rendimento mensal. Para ter a oportunidade de fazer o plantão remunerado a regra consistia em não poder faltar a nenhum dos plantões solicitados. Em caso de falta, os profissionais perderiam por três meses a possibilidade de fazer plantão remunerado e também perderiam os pontos na avaliação do Prêmio de Incentivo (PIN).

A avaliação, feita pela chefia por trimestre, considera os itens: assiduidade, interesse, cooperação/ responsabilidade e eficiência no trabalho. O PIN tem valores diferentes para as profissões. Caso a avaliação não seja feita no trimestre, os profissionais ficam sem receber. As licenças pelo INSS, ${ }^{2}$ afastamentos, aposentadorias, desligamentos, novas contratações fora do período de avaliação são situações que poderiam excluir o profissional da avaliação, impedindo-o de receber por determinado período. Os profissionais com duplo vínculo não recebem o PIN.

As faltas ao trabalho geram problemas diários para compor a escala, pois há necessidade de redistribuir pacientes e tarefas aos presentes. Em muitos casos, há necessidade de pedir emprestado um AE/ TE, ou mesmo um enfermeiro, de outra clínica.

A situação se agrava porque, como relataram os profissionais, há um problema de falta de efetivo. O hospital tem trabalhado com quadro de AE/TE já reduzido e adota como estratégia para tentar driblar faltas, licenças ou ausências em geral, o empréstimo de profissionais entre suas clínicas. Situação rela- tada como geradora de desconforto, insegurança e medo pela pressão do outro setor, como também pelo desconhecimento de detalhes técnicos que variam de uma clínica para outra, implicando em desgaste emocional por ter de trabalhar com equipe estranha e se ambientar rapidamente à situação.

Muda porque, eu estou com três anos, já tenho experiência. Mas vem uma menina nova, passou na experiência de três meses, aí ela vai emprestada para neuro. Não sei se todo mundo aqui já trabalhou para o convênio, que fica com três ou quatro pacientes e olhe lá. Não passa disso nunca. Quando tem que ficar com mais de cinco pacientes, numa neuro, que necessita de todos os cuidados ou no PS ela não vai dar conta e vai fazer alguma coisa errada.

O hospital não possui plano de carreiras para os servidores e havia um clima de competição e insatisfação permeando o ambiente em razão da futura extinção do cargo de auxiliar de enfermagem, para manter apenas o de técnico de enfermagem. Processo este que acontecia aos poucos, conforme a realização de novas contratações por concursos públicos. Os problemas, para os $\mathrm{AE}$, apesar de muitos possuírem o curso de técnico de enfermagem, era o de ter que fazer a prova de concurso público e perder a possibilidade de fazer os plantões remunerados (extras) que, à época do estudo, só eram feitos pelos AE.

Tem a questão de salário e tem a questão de serviço também. O salário é muito defasado. Para você conseguir um pouquinho a mais no salário você tem que ficar fazendo doze, doze, doze. São plantões extras porque senão seu salário vem chuuuuffff.

As situações descritas preservam ou aumentam a insatisfação pela falta de reconhecimento e de valorização profissional, pelo baixo salário, pelas pressões das chefias, por folgas que não são devidamente cumpridas em detrimento das necessidades do hospital e pela falta de efetivo.

O problema é que não tem funcionário. O problema aqui é falta de funcionário.

2 INSS, Instituto Nacional de Seguro Social, órgão governamental responsável pela administração/gerenciamento do caixa da Previdência Social, responsável pelos pagamentos das aposentadorias e benefícios previdenciários e assistenciais aos trabalhadores brasileiros. 
$\varepsilon$, final de semana reduz três funcionários para sábado e domingo, mas tem dia que é difícil.

De ruim que tem aqui é o salário em primeiro lugar. Eu acho que o estímulo maior de a pessoa trabalhar é saber que no fim do mês ela vai ter condições de pagar suas contas. Isso é uma coisa que deveria ser melhorada muito, mesmo. E outra é a desvalorização do funcionário. Nós somos muito desvalorizados, porque todo mundo tem razão. $O$ paciente, o médico, o não sei quem, o acompanhante, o periquito, o papagaio tem razão. Você nunca tem! Essaé a real.

O que égratificante éver um paciente entrar mal, eu já vi muito. Esair muito inteiro. Isso émaravilhoso.

\section{Estudo de acidente com o Modelo de Análise e Prevenção de Acidentes do Trabalho (MAPA)}

$\mathrm{O}$ acidente relatado foi escolhido considerando-se o fato de ter acontecido dentro do período do último mês de trabalho dos profissionais, à época do estudo, e por ser um tipo de acidente frequente envolvendo material perfurocortante. Também por tratar-se de acidente com elevado potencial de risco tendo em vista ter ocorrido contato com sangue infectado.

No dia do acidente, a AE envolvida trabalhava no turno da manhã (7h às 13h) e estava responsável por cuidar de seis pacientes, sendo dois acamados, dos quais um encontrava-se em quarto de isolamento respiratório. Relatou que o dia estava calmo, sem intercorrências.

Por volta de 11h45, deu início à administração das medicações das 12h. Começou pelo paciente do quarto de isolamento, pois para entrar e sair é preciso fazer a paramentação, o que exige um pouco mais de tempo para realizar os cuidados. Fez a instalação do equipo com a medicação, saiu e foi terminar as medicações dos outros pacientes. Ao terminar estas tarefas, voltou ao quarto do paciente envolvido no acidente, para verificar se a medicação havia terminado de correr. No entanto, notou que o sangue do paciente havia voltado pela extensão do equipo e precisaria realizar procedimento de limpeza para desobstruí-lo. Neste momento toca seu telefone, mas não pode atender.
Assim, saiu do quarto, foi ao posto de enfermagem, atendeu ao telefonema (seu pai, muito querido, havia sido internado). Relatou que o fato havia tirado sua atenção, seu foco. Apesar disso, preparou a bandeja com o material para limpeza do equipo (seringa, agulha, soro, algodão com álcool, luvas). Porém, antes de voltar ao quarto, parou para falar com a chefia sobre o telefonema e, como faltavam 30 minutos para o fim do plantão, resolveram que as tarefas seriam terminadas, então pegou a bandeja com o material e retornou ao quarto do paciente, no isolamento. A AE queria passar o plantão com tudo organizado, sem deixar tarefas para o próximo turno, um compromisso dos trabalhadores e também uma cobrança das chefias.

O procedimento de limpeza/desobstrução do equipo foi executado através do injetor lateral do equipo e, ao terminar de salinizar a mangueira, a profissional puxou a agulha para retirá-la do injetor, efoi atingida em um dos dedos da mão. Relatou que o paciente era agitado em razão da doença e se mexia muito (paciente considerado difícil, que alterna momentos de confusão, desorientação e exige maior vigilância); mas não saberia dizer se no momento em que puxou a agulha do injetor lateral o paciente havia se movimentado.

Em entrevistas com os profissionais do hospital, o procedimento de limpeza do equipo foi descrito como sendo rotineiro, mas com a orientação verbal para que não fosse executado utilizando-se o injetor lateral que exige o uso de agulha.

A trabalhadora acidentada não soube informar o que a levou a tomar a decisão de utilizar seringa com agulha para desobstruir o equipo, e considerou que poderia ter sido influenciada por fatores como: a) o modelo de equipo disponível e que fora instalado permitia tal manobra; b) a prática dessa manobra já fora executada com sucesso em outras ocasiões; c) a troca do equipo demoraria e, uma vez que estava próximo da passagem do plantão, poderia não ser terminada a tempo, o que afetaria a troca do turno.

Após o acidente, imediatamente, lavou as mãos e avisou a chefia, que precisaria emitir uma carta para a Direção de Enfermagem e encaminhar a acidentada a um médico, que faria a sua avaliação clínica e a do paciente fonte. No caso deste acidente, houve necessidade de tratamento, durante seis meses, com 
medicamentos fortes que lhe causavam vômitos e diarreias constantes. Ao final da profilaxia ficou constatado que não houve nenhum tipo de contaminação. A seguir o quadro síntese da Análise do acidente com perfurocortante.

Havia o risco de contaminação por material biológico no acidente. As barreiras de proteção para o caso eram frágeis ou inexistentes. Ambas dependiam de reforço ou supervisão por parte das chefias, indicando fragilidade na segurança da organização.
A descrição do trabalho real sugere que o sistema não adotava medidas de "enforcement", visando à adesão dos servidores no tocante ao uso de equipamentos de proteção individual (EPI), e nem outros procedimentos de checagem dos resultados de adesão e de prevenção obtidos (Leveson, 2004; Almeida, 2006). Essa prática parecia associada ao pressuposto de que a adesão seria fruto de responsabilidade individual dos trabalhadores, o que se pode presumir até de fala da profissional acidentada:

\section{Quadro 2 - Sín))tese da análise do acidente com perfurocortante}

\begin{tabular}{|c|c|}
\hline Componente do MAPA & Sintese \\
\hline Descrição sumária & $\begin{array}{l}\text { AE sofre acidente com picada de agulha ao realizar procedimento de limpeza de equipo utilizado } \\
\text { em paciente contaminado. }\end{array}$ \\
\hline $\begin{array}{l}\text { Descrição do trabalho } \\
\text { normal / habitual }\end{array}$ & $\begin{array}{l}\text { Responsável por } 3 \text { a } 5 \text { pacientes. Variabilidade frequente no dia do AT: cuidava de seis pacientes. } \\
\text { Medicar pacientes perto do final da jornada: Inicia instalando equipo para infusão em paciente } \\
\text { em isolamento respiratório por exigir paramentação. }\end{array}$ \\
\hline $\begin{array}{l}\text { Variabilidades } \\
\text { e recuperações } \\
\text { habituais }\end{array}$ & $\begin{array}{l}\text { Paciente com insuficiência respiratória grave, agitado, demandando mais cuidados por parte } \\
\text { da equipe de enfermagem e, quando possível, cooperação de colega em procedimentos com } \\
\text { agulhas. } \\
\text { Falta equipo habitual. Equipe instala equipo disponivel, com injetor lateral (que permite } \\
\text { desobstrução com seringa). } \\
\text { o medicamento retorna pela extensão do equipo e entope-o. Correção habitual: inserir seringa } \\
\text { no injetor lateral, salinizar o equipo e, ao final, retirar a seringa resolvendo o problema. o modo } \\
\text { operatório usado deixa a mão que apoia o injetor a centímetros da agulha que é retirada. } \\
\text { Aumento de pressão de tempo: Nessas situações, na falta de margens de manobra para } \\
\text { reprogramar objetivos, tarefas ou meios disponíveis, sobra à equipe a tentativa de dar conta da } \\
\text { situação às custas de aceleração de modos operatórios. }\end{array}$ \\
\hline Análise de mudanças & $\begin{array}{l}\text { Fracasso em manobra de desobstrução do equipo entupido. Possíveis fatores atuando nas } \\
\text { origens desse fracasso: Ansiedade e nervosismo da AE; aumento da pressão de tempo associado a } \\
\text { múltiplas tarefas no cuidado a quantidade de pacientes maior que a habitual e à proximidade de } \\
\text { final de jornada; agitação psicomotora do paciente no momento da retirada da agulha do equipo; } \\
\text { equipo usado é mais rígido que o habitual, exigindo mais força na retirada da agulha. } \\
\text { Aumento de pressão de tempo: origens possíveis em múltiplos fatores. Visitar o pai internado; } \\
\text { cuidar de mais pacientes que habitualmente; corrigir incidente em final de tarefa, etc. } \\
\text { Cuidar de mais pacientes que o habitual: variabilidade frequente que o sistema maneja com } \\
\text { aumento da carga de trabalho da equipe de enfermagem, inclusive em situações de ausências ao } \\
\text { trabalho e finais de semana (quando a equipe é reduzida). } \\
\text { Falta do equipo habitual: possíveis origens em estoque permanente com outros tipos de equipo; } \\
\text { não disponibilização de agulhas com dispositivo retrátil. } \\
\text { AE mostra sinais de ansiedade e nervosismo: preocupada com a internação do pai e com } \\
\text { passagem de plantão sem pendências a serem resolvidas pela equipe que entra. Esse conjunto } \\
\text { de achados sugere falhas de gestão no tocante à divisão de pessoas e tarefas ensejando possível } \\
\text { situação de sobrecarga de trabalho e fragilização da segurança, assim como falhas na logística } \\
\text { criando situações que exigem o uso de meios (injetor lateral) reconhecidos pelo sistema como não } \\
\text { sendo os mais adequados, a despeito de representar ganho de tempo. }\end{array}$ \\
\hline
\end{tabular}




\begin{tabular}{|c|c|}
\hline Componente do MAPA & Sintese \\
\hline Análise de barreiras & $\begin{array}{l}\text { Usar seringas não retráteis: falta de barreira de prevenção com possiveis origens em dificuldades } \\
\text { financeiras vivenciadas pela gestão do sistema associadas à existência de prazo legal que tolerava } \\
\text { a não adoção de seringas protegidas e a falhas na gestão de segurança, que não desenvolveu } \\
\text { estratégias de incentivo à adoção dos dispositivos ditos seguros. Picadas de agulha tendem a ser } \\
\text { vistas como acidentes leves e sem consequências. Equipe da empresa alegou descumprimento de } \\
\text { recomendação verbal para o não uso de equipos com injetor lateral. Afirmação contradita pelo } \\
\text { fato de ser desse tipo o equipo disponível. Regra álibi. } \\
\text { A agulha perfura a luva de procedimentos: trata-se de barreira de proteção que sabidamente } \\
\text { não evita o acidente, ou seja, poderia contribuir para minimizar consequências em alguns casos. } \\
\text { Não existência de programa de gestão visando forçar a adesão do sistema às recomendações de } \\
\text { prevenção, seja de checagem das adesões seja dos resultados obtidos com a estratégia. }\end{array}$ \\
\hline Ampliação conceitual & $\begin{array}{l}\text { A análise do trabalho real revela que o sistema atua em condições de segurança fragilizadas, que } \\
\text { dependem especialmente de conhecimentos e habilidades práticas dos profissionais. o trabalho se } \\
\text { dá na presença simultânea de sobrecarga de trabalho, agitação psicomotora de paciente, pressão } \\
\text { de tempo, preocupação com notícia sobre estado de saúde do pai, uso de meios inadequados. } \\
\text { A opção por limpeza com seringa, no lugar da troca do equipo, se dá em condições já discutidas } \\
\text { na literatura como de armadilha cognitiva e também como de "bypass previsível". Em ambas as } \\
\text { situações, a suposta escolha individual por comportamento errado passa a ser explicada como } \\
\text { associada a interferências que a sequência de passos adotada na tarefa cria sobre as formas } \\
\text { psíquicas de gestão da atividade, aumentando as chances de omissões. }\end{array}$ \\
\hline Conclusão & $\begin{array}{l}\text { Acidente envolvendo picada de agulha em contato com sangue contaminado de paciente-fonte } \\
\text { (HIV e HBV), ao retirar agulha sem dispositivo retrátil, com origens em rede de múltiplos fatores } \\
\text { em interação, incluindo políticas e práticas de funcionamento com materiais inadequados, sem } \\
\text { barreiras de prevenção, lançando mão de modos operatórios perigosos, em situação de aumento } \\
\text { de pressões de tempo associados à redução de margens de manobra necessárias para lidar com } \\
\text { pacientes agitados e a constrangimentos extralaborais que ensejam ansiedade e aumento das } \\
\text { chances de erros. }\end{array}$ \\
\hline
\end{tabular}

Fonte: (Donatelli, 2013).

Você não sabe se você está fazendo certo. Eu não fiz nada de errado. $O$ errado foi na hora de tirar a agulha. Quando eu tirei daí [do injetor lateral] que me furei. Hábito. Ia ter que trocar o equipo. Ou lava e sai todo sangue dele lá para o lixo e depois coloca de novo, ou troca. Aí para não fazer tudo isso, o que eu fiz: fui na borrachinha.

As análises de barreiras identificaram que, para o caso do acidente com perfurocortante, uma possibilidade de barreira física seria o uso de outro modelo de equipo sem o injetor lateral. No acidente relatado, não havia barreira física (eficaz), por exemplo, agulha com dispositivo retrátil. As barreiras simbólicas eram frágeis, sendo que a execução das atividades dependia apenas do sucesso dos profissionais na execução dos procedimentos e das demais ações. O uso do EPI atua- va como barreira de proteção que apenas minimizava a possibilidade de contaminação depois de eventual acidente (Hollnagel, 2004; Almeida, 2008). Relatório recente nos EUA recomenda mudanças em padrões de prevenção de acidentes com possibilidades de contaminação biológica, de modo a assegurar que, nas compras de agulhas e objetos pontiagudos, empregadores ofereçam a melhor tecnologia de proteção disponível (Public Citizen, 2013).

A falta de análise quando da ocorrência de acidentes deste tipo pela equipe de segurança do hospital, além de revelar uma fragilidade da gestão de segurança, implica na perda de oportunidade de aprendizado - como, por exemplo, conhecer as variabilidades e dificuldades enfrentadas pelos profissionais no desenvolvimento das atividades de trabalho -, 
o que enfraquece as possibilidades preventivas de intervir nos determinantes dos eventos. Um desenho de alça de controle que incluísse medidas destinadas a checar as situações descritas e os seus resultados em termos de prevenção, tanto no tocante a evitar acidentes assemelhados como quanto à introdução de novos tipos de riscos e acidentes, poderia ser implementado (Leveson, 2004).

Na prática, estabelece-se situação em que o trabalho se dá sem as barreiras preconizadas, baseadas em tecnologias de prevenção contra riscos ou perigos biológicos. Resta, como prevenção, a adesão de trabalhadores a cuidados que se revelam frágeis e insuficientes.

Além disso, diferentemente da explicação tradicional que individualiza o descumprimento de norma como causa de acidentes, a análise realizada neste estudo mostra que o "bypass" acontece quando o operador avalia que enseja benefício para a atividade, uma vez que, tendo utilizado a mesma prática com sucesso no passado, elimina custos desnecessários para si. Neste sentido, há necessidade de se avaliar como o comportamento se torna um hábito. Se equipamentos, máquinas ou procedimentos de trabalho forem dotados de dispositivos de segurança que não criem dificuldades ou embaraços para a realização da atividade, eles não serão driblados, mas, se os dispositivos criarem alguma dificuldade, dependendo da necessidade e da operação, eles passarão a sofrer os "desvios". As escolhas feitas pelos trabalhadores para a execução de suas atividades guardam relação com a história de sua inserção no grupo de pessoas ao qual estão vinculados e com os comportamentos incluídos no seu repertório individual que geralmente são aceitos e reconhecidos pelo grupo (Almeida, 2008; Meisenbach, 2003).

O conjunto de aspectos citados permite inferir a ocorrência de falha na gestão de segurança do sistema. O Programa de Prevenção dos Riscos Ambientais (PPRA) para a clínica onde ocorreu o acidente com perfurocortante não indicava o uso de agulhas com dispositivo de segurança retrátil, o sistema não analisava acidentes ocorridos e se o fazia os explicava como eventos individuais. Essa condição tanto dificulta a atuação na defesa de melhorias apoiadas na lógica de segurança do trabalho como estimula acomodação e atuação meramente burocráticas, que não questionam impactos na segurança decorrentes de contribuições das práticas gerenciais mais usadas para lidar com variabilidades do desempenho do sistema. Trata-se de conduta anacrônica que não analisa acidentes com risco de contaminação biológica, ou conclui análises atribuindo culpa às vítimas, associada a uma política de prevenção centrada no indivíduo, como o uso de EPI, reforço de treinamentos e eventual punição dos funcionários, sem levar em conta os determinantes dos eventos.

A análise mostrou que, entre outras escolhas organizacionais, a decisão de atuar com equipes de trabalho reduzidas aumentava a carga de trabalho dos profissionais, estimulava a adoção de aceleração de ritmos de trabalho, fragilizando tanto a confiabilidade como a segurança do sistema. A adoção de modos operatórios acelerados, envolvendo o manuseio de pefurocortantes nas proximidades de partes do corpo, facilita a ocorrência de acidentes disparados por mudanças quase imperceptíveis. Somou-se a essa situação aspecto da gestão de materiais permitindo seja a inexistência do equipo considerado indicado e que permitira realizar o procedimento sem uso de agulha seja a existência e disponibilização de equipo apontado como não indicado que exigia o uso de agulha a ser inserida e retirada de tubo considerado mais rígido que os habituais aumentando dificuldades em sua manipulação. Referindo-se a esses tipos de situações, operadores chegam a afirmar que se desviam a atenção um segundo, podem ocasionar um acidente. Sabendo da inexistência de ser humano capaz de manter a atenção no que faz $100 \%$ do tempo, é possível afirmar que o trabalho em tais condições desrespeita características psíquicas humanas. Referindo-se a esse tipo de análise que explora aspectos da dimensão organizacional e, ao mesmo tempo, do indivíduo, Llory (1999) cunhou a expressão acidente psico-organizacional.

As variabilidades no trabalho, já carregado de variabilidades "conhecidas em ambientes hospitalares”, e as pressões de tempo e por produção são aspectos que se somam às origens dos acidentes.

\section{Considerações finais}

Com esse estudo, foi possível revelar variabilidades do cotidiano de trabalho dinâmico e cognitivo.

A ACT contribuiu para a compreensão do trabalho por meio da descrição feita pelos profissionais de saúde, auxiliando no conhecimento do trabalho habitual preconizado pelo MAPA, identificando dife- 
rentes aspectos como sobrecarga de tarefas pelo excesso de pacientes; realização de procedimentos em ritmo acelerado; fatores externos que acometeram os sujeitos envolvidos no acidente e que concorrem para seu acontecimento.

Considera-se que a ACT possa ter sido prejudicada por ter sido realizada dentro das dependências do hospital, uma vez que o método preconiza a realização das reuniões fora do ambiente de trabalho. Porém, havia a dificuldade de marcar as reuniões em lugar externo ao ambiente de trabalho, o que pode ter dificultado o aprofundamento de muitos dos temas, tais como o da dupla jornada de trabalho, o da premiação (PIN) e o entendimento da atuação conjunta de outros profissionais.

As situações relatadas permitiram colocar em evidência a fragilidade do sistema de gestão de segurança do trabalho no hospital, implicando no fato de que qualquer pequena mudança na situação de trabalho habitual, qualquer alteração nas rotinas, poderia terminar com o desfecho de um acidente ou incidente.

Também, foram apontados pontos cruciais que sugerem a necessidade da reformulação e o repensar de conceitos, práticas e políticas de gestão no hospital para que o cuidado da saúde não dê causa a acidentes e adoecimentos dos cuidadores. Considera-se necessário que a organização se aproprie de noções como a de atividade e suas variabilidades, da análise de barreiras e de mudanças.

O estudo foi desenvolvido com a ideia de ser uma primeira etapa para subsidiar as necessárias mudanças de modo a ultrapassar o diagnóstico e propiciar um processo de intervenção formativa. Esforços neste sentido, com o apoio da equipe de pesquisa, poderão concretizar no futuro uma condição mais humana e saudável para o trabalho dos cuidadores.

\section{Referências}

ALMEIDA, I. M. Trajetória da análise de acidentes: o paradigma tradicional e os primórdios da ampliação da análise. Interface: Comunicação, Saúde, Educação, São Paulo, v. 9, n. 18, p. 185-202, 2006. Disponível em: <http://www.scielo.br/pdf/ icse/v1on19/a13v1019.pdf>. Acesso em: 24 fev. 2012.

ALMEIDA, I. M. Análise de barreiras e o modelo de ressonância funcional de acidentes de
Erik Hollnagel. Revista Brasileira de Saúde Ocupacional, São Paulo, v. 33, n. 118, p. 17-31, 2008. Disponível em: <http://www.scielo.br/pdf/rbso/ v33n118/o3.pdf>. Acesso em: 24 fev. 2012.

ALMEIDA, I. M.; VILELA, R. A. G. Modelo de Análise e Prevenção de Acidentes de Trabalho M.A.P.A. Piracicaba: CEREST, 2010.

BRASIL. Lei n ${ }^{\circ}$ 7.498, de 25 de junho de 1986. Dispõe sobre a regulamentação do exercício da enfermagem, e dá outras providências. Diário Oficial da União, Brasília, DF, 26 jun. 1986. Seção 1, p. 9273. Disponível em: <http://www.planalto.gov.br/ ccivil_03/leis/L7498.htm>. Acesso em: 12 mar. 2013.

BRASIL. Ministério do Trabalho e Emprego. Gabinete do Ministro. Portaria n ${ }^{0} 485$, de 11 de novembro de 2005. Regulamenta a NR32. Diário Oficial da União, Brasília, DF, 16 nov. 2005. Seção 1, p. 6. Disponível em: <http://portal.mte.gov.br/ data/files/8A7C812D36A280ooo138812EAFCE1 ${ }_{9} \mathrm{E} 1 / \mathrm{NR}-32 \% 2 \mathrm{O}$ (atualizada\%202011).pdf>. Acesso em: 6 jun. 2012.

BRASIL. Ministério da Saúde. Secretaria de Atenção à Saúde. Departamento de Ações Programáticas Estratégicas. Exposição a materiais biológicos. Brasília, DF, 2006. Disponível em: <http://portal.saude.gov.br/portal/ arquivos/pdf/dire_trabalho_agentes_biol_zed.pdf>. Acesso em: 8 abr. 2013.

BRASIL. Ministério da Saúde. Secretaria de Ciência, Tecnologia e Insumos Estratégicos. Diretrizes gerais para o trabalho em contenção com agentes biológicos. Brasília, DF, 2010.

Disponível em: <http://portal.saude.gov.br/portal/

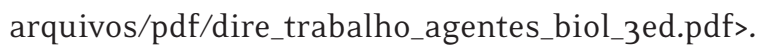
Acesso em: 8 abr. 2013.

BRASIL. Ministério da Saúde. Gabinete do Ministro. Portaria $n^{0}$ 104, de 25 de janeiro de 2011. Dispõe sobre a definição das terminologias adotadas em legislação nacional, conforme o disposto no Regulamento Sanitário Internacional 2005 (RSI 2005), a relação de doenças, agravos e eventos em saúde pública de notificação compulsória em todo o território nacional e estabelece fluxo, critérios, responsabilidades e atribuições aos profissionais e serviços de saúde. Diário Oficial da União, Brasília, 
DF, 26 jan. 2011. p. 37. Disponível em: <http://portal. saude.gov.br/portal/saude/area.cfm?id_area=1146>. Acesso em: 20 maio 2013.

BRASIL. Ministério da Previdência Social. Empresa de Tecnologia e Informações da Previdência Social. Anuário estatístico da previdência social: seção IV: acidente do trabalho. Brasília, DF, 2012. Disponível em: < http://www.previdencia.gov.br/estatisticas/ aeps-2012-anuario-estatistico-da-previdenciasocial-2012/aeps-2012-secao-iv-acidentes-dotrabalho/>. Acesso em: 19 mar. 2014.

\section{CENTRO COLABORADOR EM VIGILÂNCIA} DOS ACIDENTES DE TRABALHO. Boletim epidemiológico acidentes de trabalho com exposição potencial a material biológico. Salvador: UFBA, 2011. Disponível em: <http://www.2pontos. net/preview/pisat/hp/upload/boletim3_end.pdf>. Acesso em: 15 jan. 2012.

\section{DONATELLI, S. Análise dos acidentes com} material biológico em hospital universitário: uma abordagem a partir da análise das atividades de trabalho. 2013. Dissertação (Mestrado em Saúde Ambiental) - Faculdade de Saúde Pública, Universidade de São Paulo, São Paulo, 2013.

FERREIRA, L. L. Análise coletiva do trabalho. Revista Brasileira de Saúde Ocupacional, São Paulo, v. 21, n. 78, p. 7-19, 1993.

GARNER, J. S. Guidelines for isolation precautions in hospitals hospital infection control advisory committee. Atlanta: CDC, 1996. Disponível em: <http://wonder.cdc.gov/wonder/prevguid/ poooo419/poooo419.asp>. Acesso em: 3 abr. 2014.

HOLLNAGEL, E. Modelos de acidentes e análises de acidentes. In: BRASIL. Ministério do Trabalho e Emprego. Caminhos da análise de acidentes. Brasília, DF, 2003. p. 99-105. Disponível em: <http://portal.mte.gov.br/data/files/ FF8080812BCB2790012BD506E33953B6/pub_cne_ analise_acidente.pdf >. Acesso em: 24 ago. 2015.

HOLLNAGEL, E.; BESNARD, D. I want to believe: some myths about the management of industrial safety. Cognition, Technology \& Work, London, v. 16, p. 12-23, jul. 2012. Disponível em: <http://link. springer.com/article/10.1007\%2Fs10111-012-02374\#page-1>. Acesso em: 12 abr. 2014.
KON, N. M. et al. Acidentes de trabalho com material biológico em uma Unidade Sentinela: casuística de 2.683 casos. Revista Brasileira de Medicina do Trabalho, São Paulo, v. 9, n. 1, p. 33-38; 2011.

LEVESON, N. A new accident model for engineering safer systems. Safety Science, Amsterdam, v. 42, n. 4, p. 237-270, 2004. Disponível em: <http://sunnyday.mit.edu/accidents/ safetyscience-single.pdf >. Acesso em: 19 set. 2013. LIMA, F. P. A. Norma e atividade humana: modelos dinâmicos da prescrição e historicidade das situações de trabalho. In: DIEESE - DEPARTAMENTO INTERSINDICAL DE ESTATÍSTICA E ESTUDOS SOCIOECONÔMICOS; CESIT - CENTRO DE ESTUDOS SINDICAIS E DE ECONOMIA DO TRABALHO (Org.). Trabalho e abordagem pluridisciplinar: estudos Brasil, França e Argentina. São Paulo: Dieese; Campinas: Cesit, 2005. p. 51-68.

LLORY, M. L'Accident de la centrale nucléaire de Three Mile Island. Paris: L'Harmattan. 1999.

MACHADO, J. M. H., ASSUNÇÃO, A. A. Panorama da saúde dos trabalhadores da saúde. Belo Horizonte: UFMG, 2012.

MEISENBACH, J. Acidentes envolvendo máquinas com dispositivos de proteção: erro do usuário ou erro de concepção? Botucatu: Editora, 2003. Disponível em: <http://www.moodle.fmb.unesp.br/file.php?fil e=\%2F52\%2FMultiplicadores_Pira\%2FAcidentes_ Envolvendo_Maquinas_com_Dispositivos_de_ Protecao.pdf>. Acesso em: 19 set. 2013.

MEISSNER, A. et al. Nurses' perception of shift handovers in Europe: results from the European Nurses' early exit study. Journal of Advanced Nursing, Oxford, v. 57, n. 5, p. 535-542, 2007. Disponível em: <http://www.researchgate.net/ publication/6520999_Nurses'_perception_of_shift_ handovers_in_Europe_results_from_the_European_ Nurses'_Early_Exit_Study>. Acesso em: 10 maio 2013.

NAGAI, R. et al. Conhecimentos e práticas de adolescentes na prevenção de acidentes de trabalho: estudo qualitativo. Revista Saúde Pública, São Paulo, v. 41, n. 3, p. 404-411, 2007.

OLIVEIRA, F. A. A persistência da noção de ato inseguro e a construção da culpa: os discursos 
sobre os acidentes de trabalho em uma indústria metalúrgica. Revista Brasileira de Saúde Ocupacional, São Paulo, v. 32, n. 115, p. 19-27, 2007.

OSÓRIO, C. et.al. O trabalho cotidiano em hospitais: o ponto de vista da atividade de enfermagem. In: ASSUNÇÃO, A. A.; BRITO, J. Trabalhar na saúde: experiências cotidianas e desafios para a gestão do trabalho e do emprego. Rio de Janeiro: Fiocruz, 2011. p. 83-110.

PUBLIC CITIZEN. Health care workers unprotected: insufficient inspections and standards leave safety risks unaddressed. Washington, DC: Public Citizen's Congress Watch, 2013. Disponível em: <http://www.citizen.org/ documents/health-care-workers-unprotected-2013report.pdf $\geq$. Acesso em: 4 set. 2014.

RAPPARINI, C.; REINHARDT, E. L. Manual de implementação: programa de prevenção de acidentes com materiais perfurocortantes em serviços de saúde. São Paulo: Fundacentro, 2010.

REASON, J. Human error. Cambridge: Cambridge University Press, 1990.

SABBAH, I. et al. Occupational exposures to blood and body fluids (BBF): assessment of knowledge, attitude and practice among health care workers in general hospitals in Lebanon. Scientific Research Publishing, Irvine, v. 5, n. 1, p. 70-78, 2013. Disponível em: <http://file.scirp.org/Html/108201908_26524.htm>. Acesso em: 24 out. 2013.

SÊCCO, I. A. O. et al. A equipe de enfermagem de hospital escola público e os acidentes de trabalho com material biológico. Semina: Ciências Biológicas e da Saúde, Londrina, v. 24, p. 21-36, jan./dez. 2003. Disponível em: <http://www.uel. br/revistas/uel/index.php/seminabio/article/ view/3654>. Acesso em: 17 nov. 2011.

SIEGEL, J. D. et al. Guideline for isolation precautions: preventing transmission of infectious agents in healthcare settings. Atlanta: CDC, 2007. Disponível em: <http://www.cdc.gov/ niosh/docket/archive/pdfs/NIOSH-219/o219010107-siegel.pdf >. Acesso em: 3 abr. 2014.

SILVA, T. R. et al. Acidente com material perfurocortante entre profissionais de enfermagem de um hospital universitário. Revista
Gaucha de Enfermagem, Porto Alegre, v. 31, n. 4, p. 615-622, 2010. Disponível em: <http://seer. ufrgs.br/RevistaGauchadeEnfermagem/article/ view/14705>. Acesso em: 17 nov. 2011.

SPRICIGO, L.; MADUREIRA, V. S. F. Conhecimento da equipe de enfermagem sobre o risco ocupacional de infecção pelo HIV. Ciência Cuidado e Saúde, Maringá, v. 2, n. 1, p. 57-65, 2003. Disponível em: <http://www.den.uem.br/ v2n1p/o10_resumo.htm>. Acesso em: 17 nov. 2011.

VILELA, R. A. G. Teoria da culpa: a convivência de um modelo para perpetuar a impunidade na investigação das causas dos AT. In: ENCONTRO NACIONAL DE ENGENHARIA DE PRODUÇÃO, 23., 2003, Ouro Preto. Anais... Ouro Preto: Abepro, 2003. Disponível em: <http://www.abepro.org. br/biblioteca/ENEGEP2003_TRo408_1745.pdf >. Acesso em: 20 maio 2013.

VILELA, R. A. G.; IGUTI, A. M.; ALMEIDA, I. M. Culpa da vítima: um modelo para perpetuar a impunidade nos acidentes do trabalho. Cadernos de Saúde Pública, Rio de Janeiro, v. 20, n. 2, p. 570579, 2004. Disponível em: <http://www.scielo.br/ $\mathrm{pdf} / \mathrm{csp} / \mathrm{v} 2 \mathrm{on2} / 26 . \mathrm{pdf}>$. Acesso em: 20 maio 2013.

WHO - WORLD HEALTH ORGANIZATION. Sharps injuries: global burden of disease from sharps injuries to health-care workers. Geneva, 2003. Disponível em: <http://www.who.int/quantifying_ ehimpacts/publications/en/sharps.pdf $>$. Acesso em: 24 out. 2013 .

\section{Contribuição dos autores}

Os autores contribuíram de modo igualitário para a elaboração deste estudo.

\section{Agradecimentos}

Agradecemos aos trabalhadores do corpo de enfermagem do hospital, à equipe do SESMT gestão 2012, às chefias da Divisão de Enfermagem, à Fundacentro pela liberação para realização do estudo.

Recebido: 24/06/2014

Reapresentado: $21 / 08 / 2014$

Aprovado: 15/09/2014 